\title{
O QUE PODE UM CORPO DE RUA? EXPERIMENTAÇÕES VADIAS E POTÊNCIAS NOMADIZANTES
}

\author{
WHAT CAN THE STREET BODY DO? WANDERING \\ EXPERIMENTATIONS AND NOMAD POTENCIALS.
}

\author{
Djalma Thürler ${ }^{1}$
}

Fabio Di Rocha ${ }^{2}$

\begin{abstract}
RESUMO
O texto trata de um movimento nômade em cultura e arte com foco em novas epistemologias e que investe na diversidade dos processos inventivos e criativos propondo modos mutantes de expor, dispor e produzir o real. O "cinemavivo" que propomos, a partir da ideia de "corpos trágicos", é um cinema que não tem uma moradia fixa, que permanentemente muda de lugar e deseja quebrar com a estereotipia cromático-discursiva promovida pelo cinema-modelo, elaborada a luz da subjetividade dominante, e que nas nossas experimentações vadias, "à contrapelo", vira material potente de revide e de acerto de contas.
\end{abstract}

Palavras-chave: Artivismo. Queer. Cinema.

${ }^{1}$ Djalma Thürler é pesquisador do CLAEC - Centro Latino-Americano de Estudos em Cultura e do CULT - Centro de Pesquisa Multidisciplinar em Cultura, da UFBA. É Professor permanente do Programa Multidisciplinar de Pós-Graduação em Cultura e Sociedade e Professor Adjunto do Instituto de Humanidades, Artes e Ciências (IHAC) da Universidade Federal da Bahia. É Doutor em Letras com estudos nas áreas de Literatura Brasileira e Teatro (UFF), Mestre em Ciência da Arte (UFF) e Bacharel em Artes Cênicas. E-mail: djalmathurler@uol.com.br. Salvador. BA. Brasil.

${ }^{2}$ Fabio Di Rocha é mestre pelo Programa de Pós-Graduação Multidisciplinar em Cultura e Sociedade do Instituto de Humanidades, Artes e Ciências (IHAC) da Universidade Federal da Bahia. E-mail: rochagomes@ hotmail.com. Salvador. BA. Brasil. 


\section{ABSTRACT}

The text is a nomadic movement in art and culture with a focus on new epistemologies and investing in the diversity of inventive and creative processes proposing changing modes of display, available and produce the real. The "cinemavivo" we propose, from the idea of "tragic bodies" is a film that does not have a fixed housing, which permanently changes the place and want to break with the chroma-discursive stereotype promoted by cinema-style, elaborate light the dominant subjectivity, and in our sluts trials, the "contrapelo", turns powerful material retribution and reckoning.

Keywords: Ativism. Queer. Movie Theater. 
“Quem experimenta? O corpo. Quem inventa? Ele!"

(Michel Serres)

Começar pelo meio, onde as coisas ganham velocidade. Começar então pelo meio que é esse devir e falar em devir é falar daquilo que não tem um centro, que não segue um modelo, nenhuma regra e, portanto, não pode ser julgado.

Esse devir-texto é tanto um empreendimento estético, quanto uma analítica do desejo cinemático no campo social, um plano de composição híbrido - entre a experimentação cinemática e as notas de seu procedimento - encruzilhada temática da arte-política e o campo mórfico dos estudos interdisciplinares. A partir de um movimento que investe num pensamento, escritura e ação inventivos, intentamos problematizar os modos de produção de subjetividade na contemporaneidade, e seus estranhos "corpos trágicos", contrários aos modelos serializados e normatizados no social, além de dar visidizibilidade à uma montagem dos atravessamentos do "cinemavivo"3, sua realidade intensiva como campo de expressão, suas cenas, seus acontecimentos, seus furores, seus discursos da/sobre/com a cidade de Salvador, e as forças que atravessam e constituem o presente dessa cidade em sua materialidade.

Nossa escolha é, não resta dúvidas, uma opção política e teórica simultaneamente e, nesse sentido, certos fundamentos do pensamento da diferença - antinormatizadores por natureza - incitam-nos a trabalhar com a potência de criação em rede, a perverter o estado de coisas, e a jorrar uma matéria de expressão em treliça, convidando-nos a flanar por diversos solos de saberes, reforçando assim, um modo de pensar fora dos limites impostos por determinada cultura, pelo organismo social já que

[...] estão aí imbricadas inúmeras camadas da realidade, tanto no plano macropolítico (fatos e modos de vida em sua

${ }^{3} \mathrm{O}$ "cinemavivo" é um conceito-práxis criado para demarcar um empirismo prático e teórico, uma ação política no campo audiovisual contemporâneo e que diz respeito, tanto a um modo de composição maquínico, quanto a seu gradiente ético, estético, técnico e político. 
exterioridade formal, sociológica) quanto no micropolítico (forças que agitam a realidade, dissolvendo suas formas e engendrando outras, num processo que envolve o desejo e a subjetividade) (ROLNIK, 2008, p. 25).

Nesse sentido, iniciamos nosso procedimento com a nossa experiência subjetiva na cidade; falar/flanar, compartilhar errâncias, permitir o atravessamento pelos signos que nos rondam, propor diálogos e análises num processo de afetação micropolítica, percebendo as relações de poder na construção dos "agenciamentos coletivos de enunciação"4 alguns pesquisadores preferem ver sujeitos - e na produção das corporeidades, além de ampliar os limites do pensar e do dizer a partir da prática cinematonômica.

No entanto, algo nestes processos parecia, aos poucos, gerar sensações de incômodo: ao elaborar esse diagrama de análise, havia uma inevitável percepção de, meramente, estar operando dentro de uma epistemologia que nos posicionava ora como pesquisadores, ora como "campo de estudos", ora como o "sujeito" e/ou "objeto", ambos, caminhos insuficientes para se refletir adequadamente sobre nossa inserção no mundo enquanto um "artista-pesquisador", por isso, progressivamente, fomos sentindo que, para produzir um trabalho crítico sobre os "corpos trágicos" $" 5$ e a cidade, seria fundamental implicar nossas próprias experiências e, assim como pensou Fábio Fernandes (2014), a arte foi contaminando a pesquisa, afirmando o tônus performático desse terreno movediço, uma escrita que, ao mesmo tempo em que questiona a rigidez do labor acadêmico, abre espaços para repensar os modelos de composição e criação, arriscando-se, a enfrentar os formatos da rígida estrutura da "academia tradicional" que, d'algum modo tendem a uma modelização metodológica, quando não, a uma adequação metodológica entre o qualitativo e o quantitativo.

\footnotetext{
4 Preferimos corroborar com Félix Gattari, que ao invés de "sujeito" prefere falar em 'agenciamentos coletivos de enunciação', pois este não corresponde nem a uma entidade individuada, nem a uma identidade social predeterminada. A subjetividade é produzida por agenciamentos de enunciação e está em circulação nos conjuntos sociais de diferentes tamanhos: ela é essencialmente social, e assumida e vivida por indivíduos em suas existências particulares. (Ver GUATTARI, F. ROLNIK, S. Cartografias do desejo. Petrópolis: Editora Vozes, 2000).

${ }^{5} \mathrm{O}$ conceito de corpo trágico será desenvolvido mais à frente. 
O primeiro passo foi pensar a cidade como nos indica Calvino (2005), ou seja, pensar a cidade que é tecida pelos discursos, seus estilhaços de "acontecimentos-cenas", e seus múltiplos terrenos "materiais e emocionais, que sugerem encontro e desencontro, ordem e desordem, moral e transgressão, afeto e dor, erótica e evitamento" (MENDES JÚNIOR, 2007, p.27) ou, ainda, a cidade como texto (FERREIRA, 2010 , p. 263), como uma textualidade da nossa atualidade, certa forma de leitura das coisas imediatas que se apresentam na intempestiva experiência mundana e isso requereria trazer nossos corpos e vivências, nossa "vida corporal que não pode estar ausente da teorização" (BUTLER, 2000, p.9).

O segundo passo foi o de lançar nosso olhar sobre a cidade de Salvador, uma urbe cheia de contradições, encantos e conflitos, cidade mergulhada no medo, no ódio, na intolerância, no ressentimento, na indignação, e também em certos afetos e revide político, ali a algures, e para aquelxs que circulam por ruas, praias, becos e vielas. Para isso, trazemos à tona o narrador-flâneur, vagabundo e errante urbano relido pela poética baudelairiana e experenciada por João do Rio e Walter Benjamin, (COUTO; MILANI DAMIÃO, 2008) mas aqui, tingido de outros tons, ritmos e cores, se afastando da arrogância e do aburguesamento de sua face dândi, mas sem perder o olhar poético e marginal.

O caminhante aqui, autônomo e desejante, distribuído em fluxos nos aproxima de João do Rio, para quem o flâneur é aquelx que tem "o espírito vagabundo, cheio de curiosidades malsãs e os nervos com um perpétuo desejo incompreensível de praticar a arte de flanar" (COUTO; MILANI DAMIÃO, 2008, p. 67), ou seja, "flanar é ser vagabundo e refletir, é ser basbaque e comentar, ter o vírus da observação ligado ao da vadiagem. Flanar é ir por aí, de manhã, de dia, à noite, meter-se nas rodas da populaça, é perambular com inteligência" (idem, p. 69), zanzar com astúcia e malandragem. Flanar aqui é, portanto, andar-ver-dizercartografar, ou seja, uma vida que está em todos os cantos, e que leva consigo, além do vivido, um procedimento e uma regra de prudência,

[...] um método de investigação que não busca desvelar o que já estaria dado como natureza ou realidade preexistente. Partimos do pressuposto de que o ato de conhecer é criador de realidade, o que coloca em questão o paradigma da representação. [...] Há uma dimensão da 
realidade em que ela se apresenta como processo de criação, como poiesis, o que faz com que, em um mesmo movimento, conhecê-la seja participar de seu processo de construção (DELEUZE, GUATTARI, 1997, p.115).

O que colocaria ênfase na incerteza da neutralidade científica, nos regimes discursivos de poder, se aproximando dos processos maquínicos pensados por Deleuze e Guattari (1997), aqueles que atravessam com sua potência criativa os meios sociais na invenção do novo e fazem-se abrir para campos que estão para além dos saberes instituídos. Com isso, os autores defendem um saber que se paute no afeto, na produção de intensidades e nos posicionamentos dos sujeitos enquanto agenciadores coletivos de enunciação, o que nos aproximou de uma abordagem transdisciplinar, donde a busca por uma rede de conceitos estéticos, históricos, performativos, políticos e queer nos levavam a uma espécie de "contramétodo", organicamente imbricado no processo,

[...] um antídoto às metodologias 'lógicas', derivadas de estruturas teóricas engessadas em seus princípios, abrindo espaço para pensar o não pensado ainda. Que não se confunda, porém, esta abordagem com a eleição fortuita e aleatória de detalhes do viver em sociedade. Pelo contrário, há sempre um enorme contínuo esforço do pesquisadorflâneur [...] em escolher o detalhe, aquilo que parece escapar do geral, que se referencia o não-idêntico, valorizando a heterogeneidade isolada, imperceptível. É uma abordagem que procura mostrar em 'negativo' a verdadeira imagem que se esconde em seus contornos, a de que o geral não deixa nunca de procurar impor a sua ordem ao particular, apresentando-se como única possibilidade. Abre-se, assim, a possibilidade de destruir a ilusão do pensamento dominante que imagina poder sempre reduzir os indivíduos a exemplares de categorias gerais (SOARES, 2007, p. 489-490 - grifo nosso).

A cartografia micropolítica como "contramétodo" já nos faz caminhantes extremamente singulares entre blocos de sensações citadinos, e nos fornece lentes críticas e clínicas contra os microfascismos crescentes, com certa potência de alegria, mas, sobretudo, uma lente grande e angular para o poder de afetar e ser afetado, que nos possibilita ver e dizer esses terrenos com indignação, frente às atrocidades contra um povo miserável, que padece forçosamente, mas, sobretudo, uma sensibilidade, uma subjetividade singular, como nos ensinam Guattari e Rolnik (2000), para os quais 
[...] é possível desenvolver modos de subjetivação singulares, aquilo que poderíamos chamar de 'processos de singularização': uma maneira de recusar todos esses modos de encodificação preestabelecidos, todos estes modos de manipulação e de telecomando, recusá-los para construir modos de sensibilidade, modos de relação com o outro, modos de produção, modos de criatividade que produzam uma subjetividade singular" (GUATTARI, ROLNIK, 2000, p. 22).

As rotas aqui traçadas são inspirações gestadas e paridas de muitas outras leituras-mergulhos feitas nos corpos vivos e desejantes, frente aos desafios da contemporaneidade, principalmente para aquelxs que lidam com multiplicidades, intensidades, experimentações, territorializações e desterritorializações, com certa nobreza de encarar a vida encurralada, ao tempo em que se esforça para fugir e expressar, viver e afirmar a vida muito além do bem e do mal, estar vivo e produzir, essa sina de seres desejantes que necessitam reinventar a qualquer custo a vida, e diante das baixezas de nosso tempo, o seu terreno existencial, tais como as cartografias sentimentais da obra de Suely Rolnik (2002; 2008), os escritos e reflexões desterrenificantes de Deleuze e Guattari (1990; 1992;1997;1998; 2007), os axiomas Nietzschianos, os pensamentos das flanâncias de Walter Benjamin (COUTO; MILANI DAMIÃO, 2008), as crônicas, narrativas e poéticas de João do Rio (1997), Ferréz (2003; 2005), os pensamentos de Denilson Lopes, as encenações da ATeliê voadOR Companhia de Teatro e muitos outros, em um desejo pulsante de revide artístico intenso, caloroso e, de certa forma, erótico com essas pessoas, suas paixões, seus afetos, seus registros, suas poesias, seus espaços-tempos, seus nós, seus movimentos imperceptíveis, suas crises e reviravoltas.

No plano de consistência metodológica que se desenha, aos poucos, vamos elegendo o sistema ao invés de estrutura, a imprevisibilidade ao invés de linearidade (acaso-construção), a transgressão ao invés da hierarquia, o intermezzo contra os ciclos com início, meio e fim, a trama neural e múltipla contra a pesquisa de pivô central, a ruptura contra a continuidade dos signos, a produção e acompanhamento de mapas ao invés de uma reprodução e decalque e (des/re)fazendo mapas que não pretendem enrijecer, nem determinar meus trajetos (pela cidade, pela pesquisa) e caminhos, mas ampliar, dinamizar, potencializar vivências, experiências, os fluxos das ruas, e os seres notívagos que perambulam feito filhos do caos, a dinâmica das ondas e das vibrações desses afetos 
que transitam por eles; tudo que experimentamos no trajeto entre a pesquisa e a realização da obra - obra aberta - um rizoma ${ }^{6}$ dos agenciamentos, gravações, reformulações imagético-sonoras, pelos livros que li, pelas sonoridades que produzi, pelos filmes que vi e me inspirei, pelas obras que observei e me afetei, pelos situacionais eventos que presenciei e pelos relacionamentos que tive, "agitando velhos conceitos estereotipados como esqueletos destinados a intimidar toda criação, [...] [não se contentando] em limpar, raspar os ossos" (DELEUZE, GUATTARI, 1997, p. 109).

Antes de ser um decalque, um modelo ou mesmo uma matriz de análise que sirva como norma para outras pesquisas-ações, o que se deseja aqui é a produção de um diagrama-cruzamento das várias forças que vão se produzindo a partir dos encontros entre os diferentes nós de uma rede já enunciada - donde emerge um mundo sem fantasmagoria e que necessariamente deve ser compartilhado como intervenção e pesquisa, experiência e performance, diferença movente e criação artística que nos arrebatou, alicerce para a produção de um "cinemavivo", "pesquisa transcendental, experimental, vital, caótica, artística, esquizopesquisa, e outros tantos nomes a serem inventados, sonhados, delirados, inspirada pelo pensamento deleuzeano da diferença" (CORAZZA, TADEU e ZORDAN, 2004, p.9), produzido a partir de uma experimentação de vadiagem, uma cartografia geopolítica de corpos trágicos no cotidiano de uma cidade esquisita.

Enquanto a Salvador cartão-postal se constitui em um mapa ordenado, um desenho pré-estabelecido, uma cena estática da vida com heróis históricos e referências subjetivas dominantes, nós optamos pela contramão, por desmanchar suas realidades, borrar suas marcas e reescrever cenas outras com diferentes afetos e novos processos de subjetivação (ROLNIK, 2008).

\footnotetext{
${ }^{6}$ Em "Mil Platôs", Deleuze e Guattari (1997) produzem o conceito "rizoma", que assume um caráter ontológico nas suas obras, e que segundo os autores o termo "rizoma" foi tomado de empréstimo a botânica, onde ele define os sistemas de caules subterrâneos de plantas flexíveis que dão brotos e raízes adventícias em sua parte inferior (exemplo: rizoma de Iris). "Um rizoma não começa nem conclui, ele se encontra sempre no meio, entre as coisas (...) (idem p.24)".
} 
Figura 1 - Gráfico do contramétodo utilizado e sugerido pelos autores.

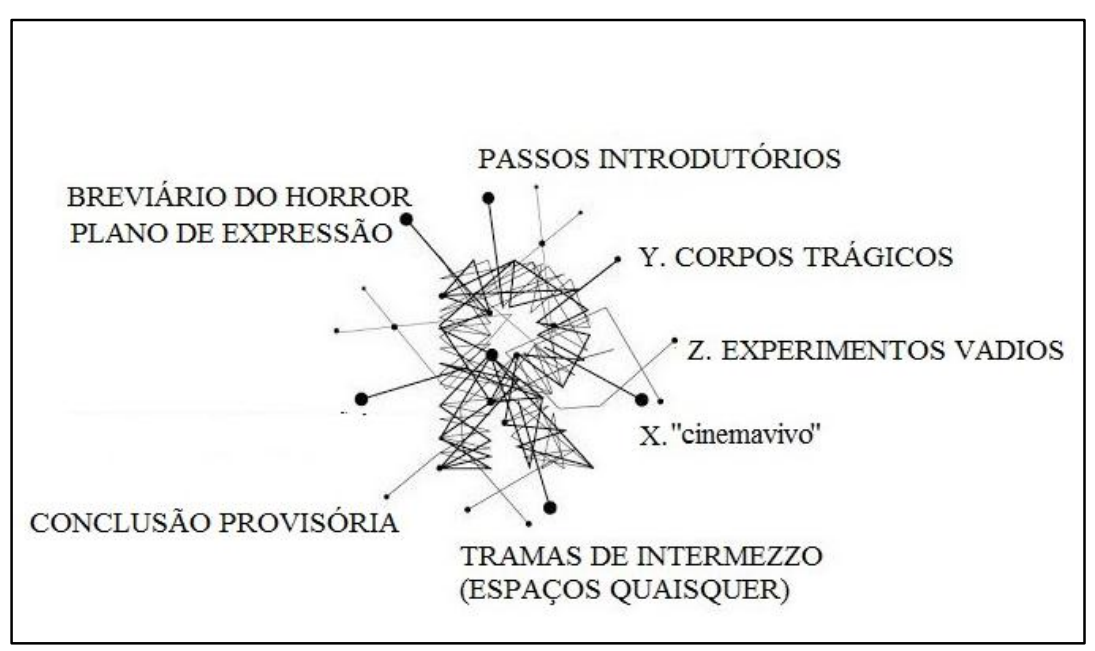

Se for correto pensarmos com Foucault, que a sociedade moderna é regulada e vigiada pelas instituições normativas, que a constituição de um sujeito se dá por meio de um conjunto de estratégias que fazem parte das práticas sociais produtoras de "corpos que pesam" (BUTLER, 2000), as verdadeiras "edificadoras da ordem", podemos dizer que essa pesquisa vai ao encontro dos “corpos trágicos" (THÜRLER, 2016), que para Thürler

[...] é, em boa medida, o corpo abjeto, aquele que não encontra inteligibilidade no seio de uma cultura heteronormativa, racista, capacitista, que visa a subalternizar os sujeitos que resistem às suas redes de influência, mas que, d'alguma forma, tem papel importante na denúncia à ideologia colonialista responsável por grande parte da dor e da degradação humana (THÜRLER. 2016, p. 03).

Ainda segundo o autor, o "corpo trágico" é um conceito extraído da fotografia no século XIX, quando John Pultz e Anne de Mondenard (2009) se perguntavam por que certos corpos lhes obrigavam a olhar para o que não queriam ver. Essa pergunta mirava o corpo trágico, não somente o corpo decadente, fruto da pobreza, da violência, da exclusão, da loucura, da droga, da angústia e da morte, mas hoje, a ideia de "corpo trágico" é mais ampla e seu campo de expressão 
[...] ganha potência política, na medida em que os corpos passam a ser entendidos e reconhecidos como 'campos de batalha', como palco de descontinuidades e de conflitos, excelente instrumento para se pensar situação do indivíduo na sociedade contemporânea. O corpo é um lugar de disputa de complexas pulsões morais, biológicas e políticas, um corpo a enfrentar discursos de ódio, cujos propósitos residem, em grande medida, na desqualificação do sujeito, na injúria à sua subjetividade, no insulto que desassujeita (THÜRLER, 2016, p. 03).

O corpo trágico não é o corpo funesto e catastrófico, nem tampouco um corpo pessimista e esperançoso, como nos diz Vladimir Jankélevitch (apud ROSSET, 1989, 42), o trágico é a aliança do necessário e do impossível. Desse modo, a atualização de Thürler (2016) diz respeito às subjetividades daquelxs que ousam se insurgir contra os regimes de assujeitamento, de minoração de si e se constitui como uma identidade cambiante e de resistência, que pulsa dos losers da sociedade, das margens - espaço de transgressões e nomadismos, e que têm na disputa e revide político em um mundo em que

[...] o que existe, portanto, não é enigma a ser dissolvido, problema a ser solucionado, fenômeno a ser explicado. Não há nada escondido, pois tudo já foi revelado. No entanto, o trágico continuará a ser sempre este estado de surpresa (ROSSET, 1989, p. 22).

Os experimentos vadios, portanto, estão profundamente relacionadas com a subjetividade de um bando social comprometido com a (re)contação de histórias sobre suas subjetividades, com a subversão e com o questionamento das normas de inteligibilidade, uma carta branca à potência, forçosamente um instrumento de combate. Eles situam o corpo como um lugar de acaso e caos, mas também de luta política, capaz de repensar as relações sociais nas quais estava imerso, fundar sociabilidades outras, resistir aos regimes regulatórios de gênero e sexualidade, e também de raça/etnia com o potencial de erigir um corpovoz-sujeito-de-si-mesmo ou, como sugere o antropólogo Miguel Vale de Almeida (2004), o corpo-objeto que é também agenciamento coletivo de enunciação, reflexo paradoxal entre natureza e cultura, entre indivíduo e sociedade, entre autonomia e regulação que, em suas errâncias corporais, ao deslizarem sobre a cidade, subvertem as leis, geram metamorfoses inesperadas e deslocamentos em alguns marcos simbólicos que são tão importantes para certos pesquisadores, e que aqui cai em desgraça na medida em que não operam realidade alguma.

\section{Revista Ambiralências}

V.4 4 N.8 • p. $81-100 \cdot$ Jul-Dez/2016

ISSN 2318-3888 • DOI: 10.21665/2318-3888.v4n8p81-100 
Um dispositivo no sentido mesmo em que anuncia Deleuze (1990) em seu texto "¿Que és un dispositivo?”, donde a concretude do emaranhado é o que interessa para um pensamento sem imagem, essa espécie de "novelo" ou "meada", conjunto multilinear retirado e transversalizado pelo pensamento e filosofia de Michel Foucault,

[...] composto por linhas de natureza diferente(...) processos sempre em desequilíbrio(...)submetida a variações de direção (bifurcada, enforquilhada), submetida a derivações(...)É sempre por via de uma crise que Foucault descobre uma nova dimensão, uma nova linha(...)Há linhas de sedimentação, diz Foucault, mas também há linhas de "fissura", de "fratura". Desemaranhar as linhas de um dispositivo é, em cada caso, traçar um mapa, cartografar, percorrer terras desconhecidas, é o que Foucault chama de "trabalho em terreno" (DELEUZE, 1990, p. 155). (Tradução dos autores).

Nossos "experimentos vadios" vão ao encontro dos corpos trágicos, dos corpos-objeto na deriva potencial da rua - deriva que serve como antídoto contra os aprisionamentos e modelizações da arte burguesa - e propõem, na desorganização da ordem estabelecida, expressa pela política que rege os processos de desubjetivação, cartografá-los (ROLNIK, 2008, p. 26), positivando-se, assim, nesses experimentos, o termo subversão como uma realidade que implica linhas de forças, que "operam idas e vindas entre o ver e o dizer e inversamente, agindo como setas que não cessam de penetrar as coisas e as palavras, que não cessam de conduzir à batalha" (DELEUZE, 1990, p. 157), capazes de minar a tênue, mas rígida fronteira que assegura a estabilidade e a ordem dos corpos e dos desejos. Portanto, é um dispositivo que envolve diversas linhas em seu mapa: linhas políticas, estéticas, éticas, materiais, críticas, clínicas, imateriais; linhas de produção, exibição, distribuição e a um só tempo, linhas de fuga, de força e de fissura.

Cartografias de sarjeta, vadiagens provisórias e malandras: uma cena sobre a outra, um ritmo contra o outro, surdina contra ruído, jorro e contenção - esperamos, mas sem esperança - arraste, arrase e afunde ainda mais as políticas identitárias e a questione o conceito de cultura, sobretudo a cultura de massa, dos mercados de poder, dos mercados econômicos, dos indivíduos normalizados, que nesse sentido

[...] é profundamente reacionário. É uma maneira de separar as atividades semióticas (atividades de orientação 
do mundo social e cósmico) em esferas, às quais os homens são remetidos. Tais atividades, assim isoladas, são padronizadas, instituídas potencial ou realmente $\mathrm{e}$ capitalizadas para o modo de semiotização dominante - ou seja, simplesmente cortadas de suas realidades políticas (GUATARRI; ROLNIK, 2000, p.68).

E trate de expor através de uma desmontagem, estratos e segmentaridades, linhas de fuga e intensidades que não ousam dizer o nome, tais como as corporeidades dos indivíduos fragmentados da pósmodernidade, das "vidas minúsculas" (MICHON, 2004) evidenciadas por seus corpos trágicos não sujeitados, ínfimos, insignificantes, infames, "vidas breves, encontradas por acaso em livros e documentos", "vidas singulares, tornadas, por não sei quais acasos, estranhos poemas" (FOUCAULT, 2006B, p. 203-204).

$\mathrm{Na}$ esteira desse e outros autores dos fluxos, fazemos uma leitura cartográfico-cinemática semelhante à cartografia de Felix Guattari e Suely Rolnik (2000) e muito parecido com o que faz Paola Berenstein Jacques (2006) no texto originalmente escrito para a revista "Le Passant Ordinaire" (2004), no sentido de colocar a errância, a nomadologia, os fluxos e forças citadinos em cena, e nesse movimento da cidade dos fluxos, tal como vemos no trecho do texto, em português: Elogio aos errantes. Breve histórico das errâncias urbanas, segundo a qual

[...] dentre os errantes e nômades urbanos encontramos vários artistas, escritores ou pensadores que praticaram errâncias urbanas. Através das obras ou escritos desses artistas é possível se apreender o espaço urbano de outra forma, partindo do princípio de que os errantes questionam a construção dos espaços de forma crítica. O simples ato de andar pela cidade pode assim se tornar uma crítica, direta ou indireta, ao urbanismo enquanto disciplina prática de intervenção nas cidades. Esta crítica pode ser vista tantos nos textos quanto nas fotografias ou mapas produzidos por artistas errantes a partir de suas experiências do andar pela cidade. (JACQUES, 2006, p.117).

Nosso processo, uma geopolítica do "cinemavivo", busca esses errantes, os que perambulam pelas cidades grandes, pelas metrópoles e recusam o controle total, com suas táticas de revide - elemento fundamental da micropolítica do desejo. A investigação-processo em "Breviário do Horror" é, também, uma sistematização do nosso processo artístico, através de uma escritura fragmentária e em blocos - tanto textual, quando audiovisual - que resultará atravessada pela cartografia dos 
“corpos trágicos", dos bandos não-sujeitados na interatividade entre o corpo anômalo, a história social e a arte.

A errância urbana é uma apologia da experiência da cidade, que pode ser praticada por qualquer um, mas que o errante pratica de forma voluntária. O errante é então aquele que busca o estado de espírito (ou melhor, de corpo) errante, que experimenta a cidade através das errâncias, que se preocupa mais com as práticas, ações e percursos, do que com as representações, planificações ou projeções. O errante não vê a cidade somente de cima, em uma representação do tipo mapa, mas a experimenta de dentro, sem necessariamente produzir uma representação qualquer desta experiência além, é claro, das suas corpografias que já estão incorporadas, inscritas em seu próprio corpo. Esta postura crítica e propositiva com relação à apreensão e compreensão da cidade por si só já constitui uma forma de resistência tanto aos métodos mais difundidos da disciplina urbanística - como o tradicional "diagnóstico", baseado principalmente em bases de dados estatísticos, objetivos e genéricos - quanto ao próprio processo de espetacularização das cidades contemporâneas (IDEM, 2006, p.6).

O resultado das nossas vadiagens contribui para a discussão provocada por Suely Rolnik em "Geopolítica da cafetinagem" (2008), afinal, quando colocamos o próprio exercício criativo ao redor da tragicidade, do minúsculo, e permitimos a reivindicação crítica dessas vidas infames e dos arquivos que as escondem e revelam, fazendo com que o outro "deixe de ser simplesmente objeto de projeção de imagens préestabelecidas e possa se tornar uma presença viva, com o qual construímos nossos territórios de existência e os contornos cambiantes de nossa subjetividade". (ROLNIK, 2008, p. 27).

Acontecimentos-cenas, hibridismo de formato e interconectividade, fluxo de pensamento acionado por redes afetiva-neurais-concretas e entrelaçadas que crescem pelas bordas, e "são como os cristais, não se transformam e não crescem a não ser pelas bordas, nas bordas [...], pois tudo se passa na fronteira" (DELEUZE, PARNET, 1998, p.10). Cenas que perseguimos com a máquina de desejos ligada para captar a impressão do instante contra a invenção ordinária do cotidiano, um corte sempre inacabado nos costumes em comum, um plano que faltava, micro cenas que pul(s)am das ruas, e que escapam à lógica comercial do puro entretenimento, e que troçam com o método cartesiano de 
produção em arte. O "eu sinto" do cinema funcionando em espaços quaisquer, provando o sabor de uma pequena hipótese-gagueira de que o cinema-experimento não pode ser prisão, e sim ponte, e que já não se sabe onde começa nem onde termina, sabe-se apenas que se propaga e prolifera em outros sempre devenires.

Ao tratar dos corpos trágicos, em "Breviário do horror", uma questão conduzia nosso processo: como e porque questões como essas tem sido cada vez mais recorrentes nas práticas artísticas contemporâneas, sobretudo, a partir de meados da década de 1990 no Brasil? E ao tentar respondê-la, pensamos mais uma vez com Rolnik (2008), "a especificidade da arte enquanto modo de expressão e, portanto, de produção de linguagem e de pensamento é a invenção de possíveis" (2008, p. 26).

Nesse sentido, compreendendo o poder de contágio e de transformação de que é portadora a ação artística, um de nossos principais objetivos passou a ser o de colaborar, através desse modo de realização do cinema nômade, para a ampliação de outras políticas de subjetivação. Não se trata de uma tendência própria da lógica midiática e de seu princípio mercadológico, nem tampouco de glamourizar as vias vadias, as curvas e margens, muito menos tentar singularizar esses terrenos destruídos, duros, cinzentos, mas trazer através dos três estratos que compõem essa dissertação-processo um "cinemavivo", uma escrita imagético-sonora, uma escrita-performance, inspirada em muitos outros artistas e pensadores que propuseram novos-outros caminhos epistemológicos, mostrando, de mais a mais, que

[...] um artista não pode se contentar com uma vida esgotada, nem com uma vida pessoal. Não se escreve com o seu eu, sua memória e suas doenças. No ato de escrever há a tentativa de fazer da vida algo mais que pessoal, de liberar vida daquilo que a aprisiona. Há um liame profundo entre os signos, o acontecimento, a vida, o vitalismo. É a potência de uma vida não orgânica, a que pode existir numa linha de desenho, de escrita ou de música. São os organismos que morrem, não a vida. Não há obra que não indique uma saída para a vida, que não trace um caminho entre as pedras (DELEUZE, 1992, p. 178-179).

"Breviário do Horror", caso fosse uma peça de teatro, seria uma “(tecno)cena”, aquela compreendida por Djalma Thürler e Josué Leite (2016) como 
[...] uma cena capaz de criar, agenciar e produzir desejos e territórios cênicos que envolvem práticas discursivas, opera enunciados e produção de sentidos, posição e representação sobre o sujeito subalterno; uma tecnologia de agenciamentos maquínicos que ampliam os processos de subjetivação. A (tecno)cena é uma operadora de subjetividades deslizantes, permeáveis, atua na produção criativa de outras poÉticas e estÉticas existenciais como um devir-menor. Portanto, como uma economia cênica do desejo e de criação de territórios existenciais, a (tecno)cena é antes de qualquer coisa, um ato político, a arte cênica contemporânea como uma política cultural anfíbia imersa no interior de processos culturais e artísticos de relações de poder na sociedade, que se realiza como uma linhas de fuga/ fratura/ fissura (máquina de guerra menor) diante dos aparelhos de dominação e às soberanias hierárquicas. [...] Neste sentido, seu caráter anfíbio '[...] está pautado nos processos criativos que remetem a potências do devir e nas heterotopias (THÜRLER; LEITE, 2016, p. 2).

E estaria sustentada segundo Tomaz Tadeu da Silva (2011) pelos princípios analíticos elementares da Teoria Queer, para quem, pensar sob esta perspectiva "significa questionar, problematizar, contestar, todas as formas bem-comportadas de conhecimento [...]. A epistemologia queer é, nesse sentido, perversa, subversiva, impertinente, irreverente, profana, desrespeitosa" (SILVA, 2011, p.107) e fortalece a experiência dos autores em observar, sentir e praticar a cidade em busca de micronarrativas orgânicas, de breves históricos de errâncias urbanas", como pensou Paola Berenstein Jacques (2006), das criaturas ban(d)idas da cidade esquisita, criaturas errantes, prostitutas, junkies, criminosos, pedintes, bichas loucas, jogadores de sinuca, desempregados, mendigos, moleques, essa gente que forma uma exoconsistência $^{7}$ (DELEUZE; GUATARRI, 1997) para o trabalho de

\footnotetext{
${ }^{7}$ Um conceito é constituído pelo tempo e é um todo que, à sua maneira, não totaliza suas partes, permanece fragmentário na constituição de seus contornos irregulares. Seguindo Deleuze e Guattari (1997) a endoconsistência do conceito é o estado de inseparabilidade de seus componentes, apesar de sua heterogeneidade e distinção e o limite de indiscernibilidade dos componentes e sua inseparabilidade formariam a consistência interna, que faria emergir o conceito enquanto um sobrevôo. Ao mesmo tempo, um conceito sempre remete a outros conceitos e sua consistência também depende da relação entre eles. A criação e permanência do plano problemático e dos conceitos que dele fazem parte implicam a construção de pontes entre eles. Essa ligação entre os conceitos, que gera um efeito de sustentação mútua, é a sua exoconsistência. Dessa forma, a construção do plano tanto quanto dos conceitos depende deste tipo de ponte, onde as ligações entre os componentes do mesmo conceito (endoconsistência) e a ligação entre os conceitos do mesmo plano (exoconsistência) são coexistentes e contemporâneos. (DELEUZE e GUATTARI, 1997).
} 
campo, um plano de consistência dessa (tecno)cena de "corpos vibráteis" (ROLNIK, 2002) que existem na reinvenção ordinária do cotidiano, e por que não dizer, na desconstrução da civilização colonialista e da "moralina cristã" 8 da História oficialesca.

As práticas artísticas contemporâneas, por sua própria natureza de expressão e problemáticas acerca do presente, não poderiam permanecer indiferentes a esse movimento e o audiovisual vem se revelando campo privilegiado para reativar sua potência política de instauração de outros "possíveis" (ROLNIK, 2008), de adensar as discussões políticas sobre os corpos, afinal,

[...] são muitos os outros com os quais passa a confrontarse a subjetividade, outros variáveis e desconhecidos, diferentemente da familiaridade de um mundo relativamente estável a que se estava habituado. A mutabilidade da paisagem intensifica-se a tal ponto que torna-se impossível calar o estranhamento que a instabilidade produz no corpo vibrátil. (ROLNIK, 2002).

No entanto, poucos estudos partem de uma prática real e isso é o que singulariza nosso trabalho, qual seja, fazer uma investigaçãointervenção, a um só tempo, prática e teórica, uma pesquisa e um cinema de conexões, um filme-acontecimento, uma mistura de tudo o que o que experimentamos ao longo da pesquisa no próprio corpo e nas andanças pelos espaços urbanos, além de seu conteúdo acontecimental - acasoconstrução - . Notas e performances produzidas, narrativas feitas e refeitas como um pergaminho rabiscado, registros documentais, mezzo ficção e novas tecnologias incorporadas a uma certa arqueologia do processo artístico, em busca de uma cartografia de afetos, fragmentos de corpos, imagens, fotos, locações, inspirações, referências.

O "cinemavivo" é o cinema periférico, "terceiro cinema" como o queria Angela Prysthon (2009), cinema de atitude, de rebeldia estética, mas, sobretudo, rebeldia política e de ação social, cujos

[...] principais temas dos filmes do Terceiro Cinema vão ser a pobreza, a opressão social, a violência urbana das metrópoles inchadas e miseráveis, a recuperação da história dos povos colonizados e oprimidos e a constituição

\footnotetext{
${ }^{8}$ O termo "moralina" (Moralin) designa a suposta "substância" da moral, e é uma das tantas contribuições zombeteiras de F. Nietzsche ao idioma alemão. 
das nações. Os praticantes do Terceiro Cinema recusam adotar um modelo único de estratégias formais ou transformar-se em um "estilo", embora isto não tenha significado que eles estivessem alheios ao cinema mundial e à ideia de um modelo, se aberto, ao menos em linhas gerais unificador (PRYSTHON, 2009, p. 08).

Nosso protocolo de experimentação, as táticas de abordar os bandos, as matilhas que inundam a rua, os corpos que não importam e retirar daqui e dali algumas singularidades fez com que o "cinemavivo" se tornasse uma usina que interpela o cotidiano da cidade em seu estado bruto, ordinário, espécie de cinema eletrônico-experimento enrabando o cinema tradicional, work in transgress, filme-corpo capaz de afetar pelas forças da sua época e do momento preciso em que atua, passando de poder sobre a vida - biopoder e biopolítica (FOUCAULT, 1989) à potência da vida, biopotência (PELBART, 2003).

Por isso insistimos que se trata, aqui, de um movimento nômade em cultura e arte, um movimento emergente, com foco na novidade criante, e que investe na diversidade dos processos inventivos. Assim retomamos as forças imperceptíveis que compartilham e colocam em ressonância modos mutantes de expor, dispor e produzir o real. O "cinemavivo" que propomos, não somente como um cinema de borda, mas como um modus operandi singular, é um cinema que não tem uma moradia fixa, que permanentemente muda de lugar e deseja quebrar com a estereotipia cromático-discursiva promovida pelo cinema-modelo, elaborada a luz da subjetividade dominante, e que na nossa ilha de edição vira material potente, olhar transversal e de acerto de contas.

Traçando uma breve radiografia do horror, que está na origem do malestar da civilização contemporânea, fomos caminhando pelos trilhos do ódio, do rancor, do ressentimento, mas também do revide, da re-ação. Violência infanto-juvenil, nas escolas, uma sociedade "sem lugares", violências contra a mulher, o aprisionamento do sujeito contemporâneo, misoginia, misandria, preconceito visual, preconceito racial, homofobia, bullyng, xenofobia, transfobia, intolerância religiosa, cyberbullying. Violência Infinita. Violência ilimitada. O que pode a arte frente aos modos de produção de subjetividade atuais?

O nosso procedimento de pesquisa-intervenção, assim, vai no sentido de produzir um bloco de sensações imagético-sonoras-textuais que mirasse 
os novos e outros processos de subjetivação que resistem, revidam e confrontam contra a nossa época de controle e moratória ilimitada, abalam as cartografias vigentes, baseadas na ideia de indivíduo fechado em si mesmo. Para tanto, erigimos o conceito de "cinemavivo", arte minúscula contra o câncer da superfície dos acontecimentos atuais e a favor da profundidade, dos corpos trágicos, dos subterrâneos da cidade do Salva a dor, terra em transe.

\section{Referências:}

ALMEIDA, Miguel Vale de. O manifesto do corpo. Revista Manifesto, 5: p. 17-35, 2004.

BUTLER, Judith. Corpos que pesam: sobre os limites discursivos do sexo. In: LOURO, Guacira Lopes (Org.). O corpo Educado Pedagogias da sexualidade. Louro. Traduções: Tomaz Tadeu da Silva. 2 ed. Belo Horizonte: Autêntica, 2000.

CALVINO, Ítalo.As Cidades Invisíveis.Rio de Janeiro: O Globo, 2005.

CORAZZA, S. TADEU, T. ZORDAN, P. Linhas de escrita. Belo Horizonte: Autêntica, 2004.

COUTO, Edvaldo Souza; MILANI DAMIÃO, Carla. Walter Benjamin: formas de percepção e estética na modernidade. Salvador: Quarteto Editora, 2008.

DELEUZE, Gilles. Cinema II - A imagem-tempo. São Paulo: Brasiliense, 2007.

. ¿Que és un dispositivo? In: FOUCAULT, Michel. Filósofo. Barcelona: Gedisa, 1990.

. Conversações. Rio de Janeiro: Ed. 34, 1992.

DELEUZE, Gilles e PARNET, Clair. Diálogos. São Paulo: Escuta, 1998.

DELEUZE, G; GUATTARI, F. Mil platôs: capitalismo e esquizofrenia. v. 1. São Paulo: Editora 34, 1997. 
FERNANDES, Fábio. A alma encantadora do Beco ou as crônicas de um errante vagabundo. Dissertação de Mestrado. Universidade Federal da Bahia, 2014.

FERREIRA, Marcelo Santana. Textualidade da cidade contemporânea na experiência homoerótica. In: LOPES, Luiz Paulo da Moita, BASTOS, Liliana Cabral (Org.). Para além da identidade - fluxos, movimentos e trânsitos. Belo Horizonte: Ed. UFMG, 2010.

FERRÉZ (org.). Literatura marginal: talentos da escrita marginal. Rio de Janeiro: Agir, 2005.

. Manual prático do ódio. Rio de Janeiro: Objetiva, 2003.

FOUCAULT, Michel. Arqueologia do saber. Rio de Janeiro: Forense Universitária, 1989.

2006.

A Hermenêutica do Sujeito. 2. ed. São Paulo: Martins Fontes.

A vida dos homens infames. In:

Ditos e escritos. 2. ed.

Organização, seleção de textos e revisão técnica de Manoel Barros da

Motta; tradução de Vera Lúcia Avellar Ribeiro. Rio de Janeiro: Forense Universitária, 2006B.

GUATTARI, F. ROLNIK, S. Cartografias do desejo. Petrópolis: Editora Vozes, 2000.

JACQUES, Paola Berenstein. Elogio aos errantes. In: JEUDY, Henri Pierre e JACQUES, Paola Berenstein. Corpos e cenários urbanos: territórios urbanos e políticas culturais. Salvador: EDUFBA, 2006.

RIO, João do. A alma encantadora das ruas. ANTELO, Raúl (org.). São Paulo: Companhia das Letras, 1997.

MENDES JÚNIOR, Walcler Lima. A pedagogia das canções na arquitetura da cidade da música: versos, notícias e crônicas como declarações musicais da urbanidade brasileira. Estudos e Pesquisas em Psicologia. Rio de Janeiro, v.7, n. 2., dezembro de 2007.

MICHON, Pierre. Vidas minúsculas. São Paulo: Estação Liberdade, 2004.

PELBART, Peter P. Vida capital. São Paulo: Iluminuras, 2003. 
PULTZ, John; DE MONDENARD, Anne. Le corps photographié. Paris: Flammarion, 2009.

PRYSTHON, Angela. Do terceiro cinema ao cinema periférico estéticas contemporâneas e cultura mundial. Revista Periferia: Educação, Cultura e Comunicação, UERJ: Rio de Janeiro, 2009. http://www.epublicacoes.uerj.br/index.php/periferia/article/view/3421 (Acesso em 23 de outubro de 2016).

ROLNIK, Suely. Molda-se uma alma contemporânea. In: LEÃO, Lúcia (org.) Interlab - Laboratório de pensamentos contemporâneos. São Paulo: Iluminuras, 2002.

Geopolítica da cafetinagem. In: FURTADO, Beatriz. Fazendo Rizoma: pensamentos contemporâneos. São Paulo: hedra, 2008, p.25 44.

ROSSET, Clément. Lógica do pior. Rio de Janeiro, Espaço e Tempo, 1989.

SERRES, Michel. Variations sur le corps. Paris: Le Pommier, 1999.

SOARES, Jorge Coelho. Escola de Frankfurt: unindo materialismo e psicanálise na construção de uma psicologia social marginal. In: JACOVILELA, Ana Maria; FERREIRA, Arthur Arruda Leal; PORTUGAL, Francisco Teixeira (Orgs.). História da psicologia: rumos e percursos. Rio de Janeiro: Nau, 2008.

SILVA, Tomaz Tadeu da. Documentos de Identidade: uma introdução às teorias do currículo. Belo Horizonte: Autêntica, 2011.

THÜRLER, Djalma. O corpo trágico na cena contemporânea: this body matters. Bolsa FUNARTE para Formação em Artes Cênicas, Salvador, 2016.

THÜRLER, Djalma; LEITE, Josué. A (tecno-cena) como política desubjetivação. Texto inédito. Salvador, 2016.

Recebido em 14/11/2016

Aprovado em 14/12/2016 